\title{
Resposta Adaptativa de Melipona subnitida Ducke e a Termorregulação Colonial em Diferentes Condições Térmicas no Contexto das Mudanças Climáticas
}

\author{
Janevane Silva de Castro $^{1,3}$, Arnóbio de Mendonça Barreto Cavalcante ${ }^{1,2}$ (D), \\ Valber Jones de Castro $^{1}$, Emerson Mariano da Silva ${ }^{1}$ \\ ${ }^{1}$ Mestrado Profissional em Climatologia e Aplicações nos Países da CPLP e África, \\ Universidade Estadual do Ceará, Fortaleza, CE, Brasil. \\ ${ }^{2}$ Instituto Nacional de Pesquisas Espaciais, Eusébio, CE, Brasil. \\ ${ }^{3}$ Centro de Ciências Agrárias, Universidade Federal do Ceará, Fortaleza, CE, Brasil.
}

Recebido em: 25 de Abril de 2019 - Aceito em: 3 de Junho de 2019

\begin{abstract}
Resumo
Efeitos negativos decorrentes do aquecimento do sistema climático têm sido relatados para diferentes espécies de abelha. Dada a importância econômica, social e ambiental das abelhas, particularmente, para o bioma Caatinga, necessário se faz conhecer potenciais efeitos negativos a fim de orientar medidas eficientes de adaptação desses animais frente às mudanças climáticas. $\mathrm{O}$ objetivo desse estudo foi identificar efeitos decorrentes do aumento da temperatura externa sobre a homeostasia e o comportamento das colônias de Melipona subnitida Ducke (jandaíra). Para tal, considerou-se dois tratamentos distintos CRDS (Colônias nidificadas recebendo Radiação Direta do Sol) e CNSS (Colônias Nidificadas Sob área Sombreada). O parâmetro avaliado foi o comportamento forrageiro das abelhas, além de comparar as temperaturas internas de cada colmeia com a temperatura exterior. O estudo apontou que as colônias CRDS sofreram redução considerável na capacidade defensiva da colmeia, bem como no comportamento forrageiro de entrada, além de indiciar mais dificuldade na termorregulação das colmeias e adaptação a essa condição, quando comparadas as colônias CNSS. Portanto, parece razoável sugerir que colmeias de jandaíra sejam locadas em áreas de sombreamento natural perene, como uma medida de ajuste ao aumento da temperatura ambiente corrente.
\end{abstract}

Palavras-chave: jandaíra, abelha nativa, impacto ambiental, temperatura.

\section{Adaptive Response of Melipona subnitida Ducke and Colonial Thermoregulation in Different Thermal Conditions in the Context to Climate Change}

\begin{abstract}
Negative effects of climate system warming have been reported for different bee species. Given the economic, social and environmental importance of bees, particularly for the Caatinga biome, it is necessary to know potential negative effects in order to guide efficient measures of adaptation of these animals to the climatic changes. The objective of this study was to identify effects arising from the increase of external temperature on homeostasis and the behavior of the colonies of Melipona subnitida Ducke (jandaíra). For this, two different treatments were considered CRDS (Nesting colonies receiving Direct Radiation from the Sun - Portuguese acronym) and CNSS (Nested Colonies Under Shaded Area - Portuguese acronym). The evaluated parameter was the forage behavior of the bees, besides comparing the internal temperatures of each beehive with the outside temperature. The study pointed out that the CRDS colonies suffered a considerable reduction in the defensive capacity of the hive, as well as in the entrance fodder behavior, besides indicating more difficulty in the thermoregulation of the hives and adaptation to this condition, when compared to the CNSS colonies. Therefore, it seems reasonable to suggest that jandaíra hives are leased in areas of natural perennial shading, as a measure of adjustment to the increase in the current ambient temperature.
\end{abstract}

Keywords: jandaíra, native bee, environmental impact, temperature.

Autor de correspondência: Arnóbio de M.B. Cavalcante, arnobio.cavalcante@inpe.br. 


\section{Introdução}

O tema mudanças climáticas associado ao aquecimento global, ganhou protagonismo científico mundial devido, dentre outras razões, aos seus impactos negativos imediatos e futuros sobre a biodiversidade global. $\mathrm{O}$ aquecimento do sistema climático global é inequívoco (IPCC, 2014) e já está provocando alterações em diversos ecossistemas do planeta (Bellard et al., 2012; CBD, 2016; Pecl et al., 2017).

Os grandes biomas do mundo com predominância de flora e fauna específicas em uma considerável extensão de terra resultam de relações estreitas entre o clima, relevo, solo, vegetação e as espécies animais. É notável que, com a intensificação do aquecimento global vários biomas ao redor da Terra já estão passando por transformações, dando indícios de mudanças que podem levar, por exemplo, a aridização do bioma Caatinga (Marengo, 2008 e 2014; Lacerda et al., 2016; Marengo et al., 2017). Para o bioma Caatinga, único no mundo e inserido predominantemente na região Nordeste, projeta-se uma tendência de aumento da temperatura em até $4,5^{\circ} \mathrm{C}$ e redução da precipitação em $50 \%$ até o final desse século (BRASIL, 2016a).

As mudanças climáticas estão em curso, continuarão atingindo o bioma Caatinga e os estudos disponíveis são insuficientes para uma avaliação adequada dos efeitos, para o presente e para o futuro. E, essa insuficiência no conhecimento é preocupante, haja vista ao diagnóstico do Quinto Relatório Nacional sobre a Biodiversidade (BRASIL, 2016b) que classificou o bioma Caatinga como o quarto bioma mais devastado do país, com $53,4 \%$ de vegetação nativa remanescente. Ademais, causa inquietação o fato de a Caatinga ter sido incluída recentemente na lista das regiões do mundo mais sensíveis ecologicamente à variabilidade climática, juntamente com a tundra ártica, partes da faixa de floresta boreal, a floresta tropical dentre outras (Seddon et al., 2016).

Em síntese, ao reunir mudanças climáticas em curso, tendência à aridização, conhecimento incipiente nessa questão, destruição antropogênica e vulnerabilidade, o que se espera para a biodiversidade do bioma Caatinga no futuro é, certamente, um cenário de colapso total caso nenhuma ação efetiva humana preventiva seja realizada. Diante dessa visão apocalíptica de futuro, é urgente e imperativo avançar em estudos que forneçam informações que venham a melhorar nossa compreensão sobre os potenciais efeitos negativos das mudanças do clima sobre as espécies do bioma Caatinga. Nessa direção, é oportuno focar-se nas abelhas, dada sua importância social, econômica e ambiental em qualquer parte do mundo e registrar um expressivo declínio de populações em vários países (CaraDonna et al., 2018).

Para as abelhas o efeito da flutuação da temperatura pode atingir diretamente sua permanência em alguns biomas, visto que esses insetos são ectodérmicos, ou seja, necessitam da temperatura do ambiente onde estão inseridas para regular a temperatura corpórea. Porém, muitas espécies vivem em sociedades formadoras de colônias e, ao longo do tempo foram desenvolvendo artifícios para que conseguissem manter a homeostasia colonial, independendo por parte, da temperatura externa da colmeia. Todavia, para que esse processo ocorra, assim como acontece com os animais vertebrados, há um maior gasto de energia, além de afetar a captura dos recursos, havendo uma relação direta entre a temperatura interna e externa das colmeias na manutenção da colônia (Lima, 2016). Dessa maneira, torna-se relevante saber o modo como o aquecimento da temperatura externa à colmeia pode influenciar na homeostasia, bem como na termorregulação colonial e nos trabalhos de alimento e água.

O objetivo desse estudo foi identificar potenciais efeitos negativos decorrentes do aumento da temperatura externa à colmeia, sobre a homeostasia e o comportamento das colônias de Melipona subnitida Ducke (abelha nativa), tendo em vista contribuir com informações que melhorem nas medidas preventiva e corretiva de adaptação para abelhas, frente aos cenários de mudanças do clima no bioma Caatinga.

\section{Material e Métodos}

\subsection{Local de estudo e espécie}

$\mathrm{O}$ experimento foi realizado em um sítio localizado no distrito de Cauaçu, município de Eusébio, estado do Ceará, com coordenadas geográficas $3^{\circ} 51^{\prime} 08.7^{\prime \prime} \mathrm{S}, 38^{\circ}$ $28^{\prime} 38.6^{\prime \prime} \mathrm{W}$ e altitude de $28 \mathrm{~m}$ acima do nível do mar. O sítio experimental encontrava-se em um local bem arborizado com presença abundante de arbóreas frutíferas (mangueira, cajueiro e coqueiro) e nativas (carnaúba, jurema e sabiá), com poucas residências nas proximidades e a cerca de $350 \mathrm{~m}$ de distância da mata ciliar do rio Coaçu.

A espécie estudada, Melipona subnitida Ducke, popularmente conhecida como jandaíra ou jandaíra do Nordeste, é uma abelha tropical sem ferrão (ferrão atrofiado), endêmica do Nordeste do Brasil e que apresenta grande potencial para produção de mel e pólen, além de ser um dos principais polinizadores do bioma Caatinga (Bonatti et al., 2014). Essa espécie de abelha não consta na lista do Livro Vermelho da Fauna Brasileira Ameaçada de Extinção (ICMBio, 2018).

\subsection{Procedimento experimental}

Foram utilizadas oito colônias de abelhas jandaíra (dois tratamentos com quatro repetições), com rainhas de mesma idade e de mesma origem, a fim de eliminar o efeito da genética. As colônias foram avaliadas em duas condições térmicas de um mesmo meliponário, sendo um grupo de colônias exposto à radiação direta do sol (CRDS - Colônias nidificadas recebendo Radiação Direta do Sol) 
e o outro grupo alocado em área com sombreamento natural (CNSS - Colônias Nidificadas Sob área Sombreada) durante todo o dia.

As CNSS ficaram em uma área totalmente sombreada de uma árvore de copa frondosa (mangueira), de modo que não receberam radiação solar de forma direta, enquanto que as CRDS ficaram em uma área totalmente exposta a radiação solar de maneira direta e durante todo o dia, sem sombreamento algum. As colônias foram nidificadas em caixas de criação padronizadas, enumeradas e confeccionadas em madeira, com espessura de $2 \mathrm{~cm}$ para todas as peças e pintadas com tinta d'água de cor branca em sua parte externa. Em cada um dos tratamentos (CNSS e CRDS) as referidas caixas (quatro para cada tratamento) com as colônias nidificadas foram alocadas em cima de uma mesa de madeira projetada e fixada no solo a uma altura de 1,60 m. Os dois tratamentos foram separados a uma distância de aproximadamente $50 \mathrm{~m}$, bem como as caixas de cada tratamento foram justapostas a $20 \mathrm{~cm}$ de distância uma da outra.

A temperatura dentro das caixas (temperatura interna) foi monitorada por sensores térmicos (modelo: $\mathrm{DS} 18 \mathrm{~B} 20$, com precisão de $\pm 0,01{ }^{\circ} \mathrm{C}$ ) à prova $\mathrm{d}$ água, sendo um em cada caixa, conectados a um microcontrolador (modelo: ESP8266) que registrou as temperaturas a cada meia hora e armazenou essas informações durante todo o experimento. Foi utilizado um servidor com sistema Linux com cliente NTP (Network Time Protocol) configurado para utilizar os servidores do $n t p . b r$ (relógios atômicos), onde por meio de um shell script o servidor consultava as temperaturas da interface web dos microcontroladores.

O acompanhamento da temperatura ambiente dos dois tratamentos (temperatura externa) foi realizado utilizando-se dois termohigrômetros (modelo: IP-747RH) com datalogger embutido que também realizaram leituras a cada meia hora, coincidentes aos horários dos sensores térmicos internos das colmeias e armazenou essas informações durante o todo o tempo de duração do experimento.

As temperaturas internas de cada colônia (de cada tratamento) foram comparadas com as temperaturas do ambiente externo (de cada tratamento) para que fosse possível mensurar a forma como as jandaíras iriam termorregular as colmeias. O tempo de duração do experimento inteiro foi de 60 dias $(05 / 11 / 17$ a $05 / 01 / 18)$ para garantir que no tempo de análise ocorresse a troca de, no mínimo, uma geração dos indivíduos dentro da colônia.

\subsection{Análises}

Para o comportamento forrageiro das abelhas ao longo de todo o período experimental, foi realizada uma vez por semana, uma avaliação da atividade de coleta das abelhas pelo método de comportamento do tipo animal focal. Para tanto, duas pessoas treinadas (uma para cada tratamento) fizeram a observação contínua por 5 min a cada hora, para cada repetição, ao longo do dia, no período das 7 às $18 \mathrm{~h}$ observando e anotando o número de abelhas que entra na colmeia carregando pólen, néctar e/ou água. Foram avaliadas todas as colônias repetindo essa mesma mensuração durante o tempo do experimento.

Referindo-se à análise estatística, o delineamento experimental foi o inteiramente casualizado com parcelas subdivididas, analisadas com auxilio do programa SAS, submetidos ainda à análise de variância (ANOVA) e aplicado o teste de Tukey a $5 \%$ de probabilidade.

\section{Resultados e Discussão}

\subsection{Observações gerais}

Durante a realização das análises experimentais foi possível perceber alguns comportamentos relevantes das colônias dos tratamentos CNSS e CRDS. Inicialmente, foi observado que nos dias de análise de comportamento forrageiro em que ocorreu precipitação $(17 / 11 / 17,24 / 11 / 17$ e $23 / 12 / 17)$, as abelhas de ambos os tratamentos reduziram e até mesmo zeraram, as atividades de entrada e saída durante o intervalo em que precipitava. Notou-se que a redução foi mais acentuada nas colmeias CRDS, levando a inferir que a ausência de sombreamento facilita a percepção de chuva.

Observou-se também que todas as análises de comportamento forrageiro de todas as colmeias CNSS e CRDS foram zero no horário das $18 \mathrm{~h}$ (momento o qual já não havia mais luz natural), evidenciando que ao final do dia as atividades de entrada das abelhas cessam. Segundo von Frisch (1976), as abelhas são insetos que se orientam através da luz solar, daí as abelhas recolherem-se para a colmeia normalmente ao final do dia e, de maneira geral, as abelhas saem para forragear logo aos primeiros raios solares.

Outro fato interessante observado foi o comportamento agressivo das abelhas do tratamento CNSS no momento da abertura das caixas (realizada quinzenalmente para averiguar se havia presença ou não de predadores - formigas, cupins etc.), embora isso não tenha ocorrido na abertura das caixas do tratamento CRDS. Apesar das abelhas jandaíras não possuírem ferrão, elas possuem mecanismos de defesa que consistem em "beliscões" relativamente dolorosos na pele causando incômodo e dificultando a realização da análise.

Um estudo realizado por Shackleton et al. (2015), evidenciou que apesar dessas abelhas serem incapazes de ferroar como as Apis mellifera, elas apresentam outros mecanismos de defesa. Um desses mecanismos consiste em "morder" com tanta persistência um alvo intruso ao ponto de não se desprender e morrer durante o ataque, sacrificando-se para proteger a colônia do saque de seu alimento por outras abelhas "ladras", da predação por 
outros animais ou mesmo da presença humana. Ademais, o comportamento agressivo é comum em colônias fortes, com população que variando entre 700 a 1000 abelhas, onde elas defendem com vigor a colmeia quando manejada, atacando e beliscando o intruso.

Dessa forma, é possível inferir que de algum modo as abelhas jandaíras expostas diretamente ao sol (CRDS) podiam não estar em boas condições de desenvolvimento colonial (não se desenvolvendo a ponto de tornarem-se superpopulosas) ou ainda, que o estresse da temperatura leva esses insetos a uma condição de que reduz a força defensiva deles em relação à colônia. Caso a última suposição seja verdadeira, é possível que o estresse de um aumento na temperatura média (que ocorra em curto prazo) no bioma Caatinga, possa levar esses insetos a uma perda de capacidade defensiva da colônia, facilitando a predação por outros animais e podendo causar impactos na manutenção da mesma frente à maior vulnerabilidade.

\subsection{Comportamento forrageiro das abelhas}

Foi possível inferir que a atividade de entrada das abelhas nas colmeias é mais intensa durante as primeiras horas do dia, principalmente, até às $7 \mathrm{~h}$. Logo após esse horário há um declínio na média da quantidade de abelhas que entram. Entre 10 e $12 \mathrm{~h}$ há novamente uma entrada maior das abelhas nas colmeias e ao entardecer, após as 16 h, há uma queda na entrada de abelhas. Em ambos os tratamentos o comportamento entre os horários é similar, no entanto, o tratamento CNSS apresentou maior quantidade de abelhas entrando nas colmeias. Esse dado é importante, pois apontou que as condições climáticas do tratamento CNSS são mais favoráveis as atividades de forrageamento que as do tratamento CRDS (Fig. 1).

Estabelecendo o nível de significância de 0,05 , conclui-se que houve diferença significativa $(p=0,02)$ entre os tratamentos CRDS e CNSS. Feita avaliação através do teste de Tukey, restou que o tratamento que possuiu a maior média de entrada de abelhas durante o experimento foi o CNSS (com média igual a 1,94), enquanto o CRDS foi de 1,62 .

\subsection{Temperatura interna das colmeias}

A Fig. 2 mostra como a temperatura interna média das colmeias variou em $24 \mathrm{~h}$ ao longo do experimento e por tratamento. $\mathrm{O}$ comportamento entre as temperaturas internas dos tratamentos é visto, grosso modo, de forma similar quanto ao desenho da linha, isto é, uma constância, uma elevação e novamente uma constância. No entanto, é bem nítido que as colônias CRDS apresentaram valores mais elevados de temperatura interna do que as colônias CNSS entre 8 e $16 \mathrm{~h}$, conferindo além de uma maior temperatura interna também, uma maior amplitude térmica. Após esse período a temperatura interna média das colônias CNSS apresentaram valores ligeiramente superiores que as colônias CRDS.
É perceptível através na figura acima que as colônias CRDS possuem maior temperatura interna durante o dia, porém durante a noite o comportamento se inverte e as colônias CNSS passam a ter maiores temperaturas internas. Isso nos faz inferir que abelhas expostas durante muito tempo a temperaturas ambientes mais elevadas (tratamento CRDS), se dediquem mais a manter a termorregulação colonial durante o dia do que a noite, até como forma de refrigerar mais a colmeia diante da grande amplitude térmica a qual estão expostas. Estabelecendo o nível de significância de 0,05 , nota-se que há diferença significativa $(\mathrm{p}<0,001)$ entre os tratamentos. Aplicando o teste de Tukey confirmou-se de fato a diferença significativa entre os tratamentos (CRDS e CNSS) entre os horários de 7 e $17 \mathrm{~h}$, tendo o tratamento CRDS a maior média de temperatura interna das colônias $\left(33,84^{\circ} \mathrm{C}\right)$, enquanto o tratamento CNSS obteve a média igual a $30,18^{\circ} \mathrm{C}$.

\subsection{Temperatura externa (ambiente) dos tratamentos}

O comportamento entre as temperaturas externas dos tratamentos é visto de forma similar quanto à curvatura da linha o gráfico (Fig. 3). No entanto é notável que o tratamento CRDS apresentou valores de temperatura externa (ambiente) mais elevados do que o tratamento CNSS. Isso conferiu ao tratamento CRDS uma amplitude térmica externa bem maior que o tratamento CNSS, mostrando que o sombreamento de fato interfere intensamente na temperatura ambiente do tratamento, principalmente no período da manhã entre às $6 \mathrm{e} 18 \mathrm{~h}$.

Foi observado também que no tratamento CNSS existiu uma pequena redução na temperatura média externa entre as 7 e $8 \mathrm{~h}$ da manhã, durante todos os dias do experimento. $\mathrm{O}$ fato pode ser explicado por nesse intervalo os raios solares estarem deixando de incidir diretamente sobre o termohigrômetro e passando a incidir numa inclinação onde existe a copa (folhagem) lateral da mangueira mais densa, causando um efeito de refrigeração maior momentâneo, onde logo após esse interim o processo se normaliza. Nota-se também que durante a noite (entre 19 e $6 \mathrm{~h}$ ) a presença de sombreamento praticamente não interfere na temperatura externa (ambiente).

Estabelecendo o nível de significância de 0,05 podemos inferir que há diferença significativa $(\mathrm{p}=0,02)$ entre os tratamentos na temperatura externa média das colônias durante o dia inteiro $(24 \mathrm{~h})$. Avaliando também através do teste de Tukey, confirma-se que a diferença é significativa, com o tratamento CRDS possuindo a maior média de temperatura externa $\left(29,34{ }^{\circ} \mathrm{C}\right)$ enquanto a do tratamento CNSS foi de $27,80^{\circ} \mathrm{C}$.

Avaliando a média dos horários entre 7 e $17 \mathrm{~h}$ avaliadas e estabelecendo o nível de significância de 0,05 , observou-se que também houve diferença significativa $(p<0,001)$ entre os tratamentos CNSS e CRDS na temperatura externa (ambiente) média das colônias. Através do teste de Tukey confirmou-se a diferença significativa 


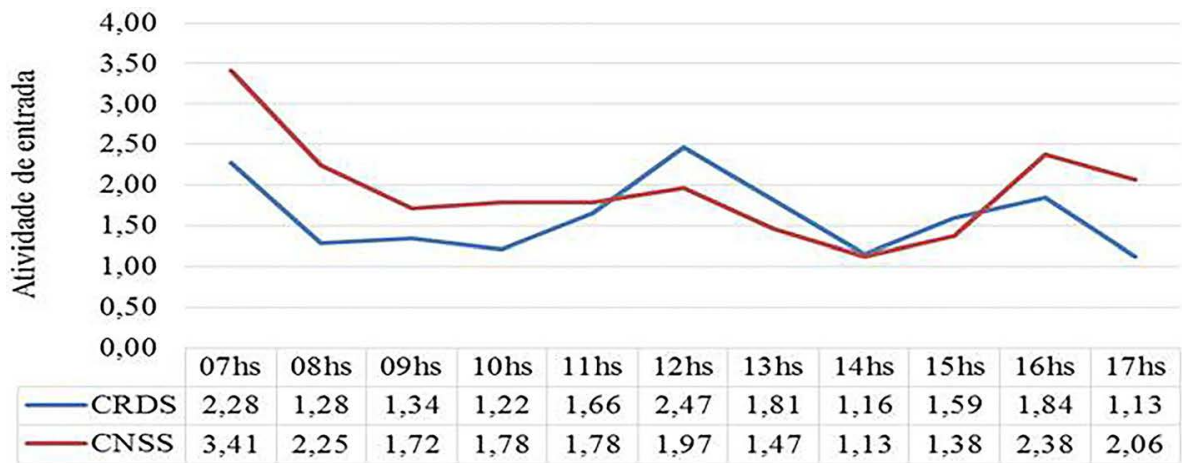

Figura 1 - Distribuição da média do comportamento forrageiro (número médio de abelhas) na atividade de entrada das colmeias nos tratamentos CRDS e CNSS conforme os horários.

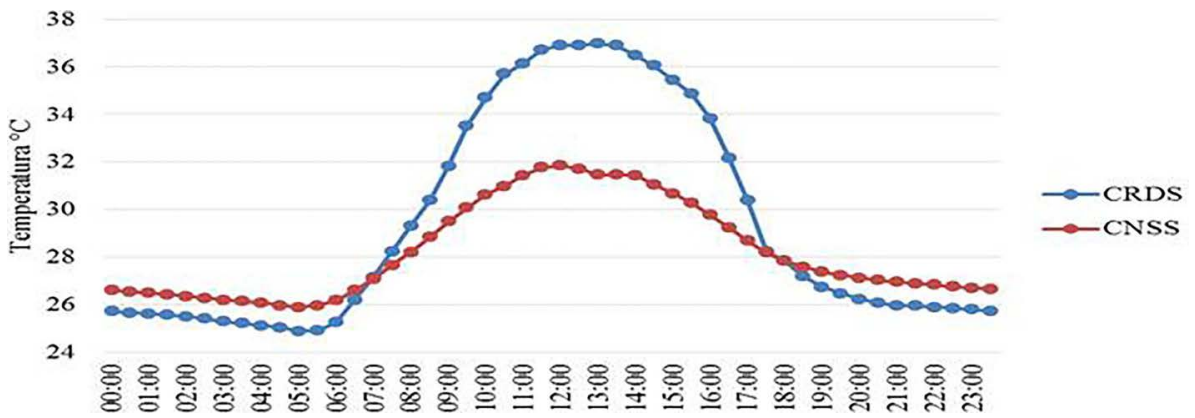

Figura 2 - Distribuição da média da temperatura interna das colônias por tratamento e hora do dia.

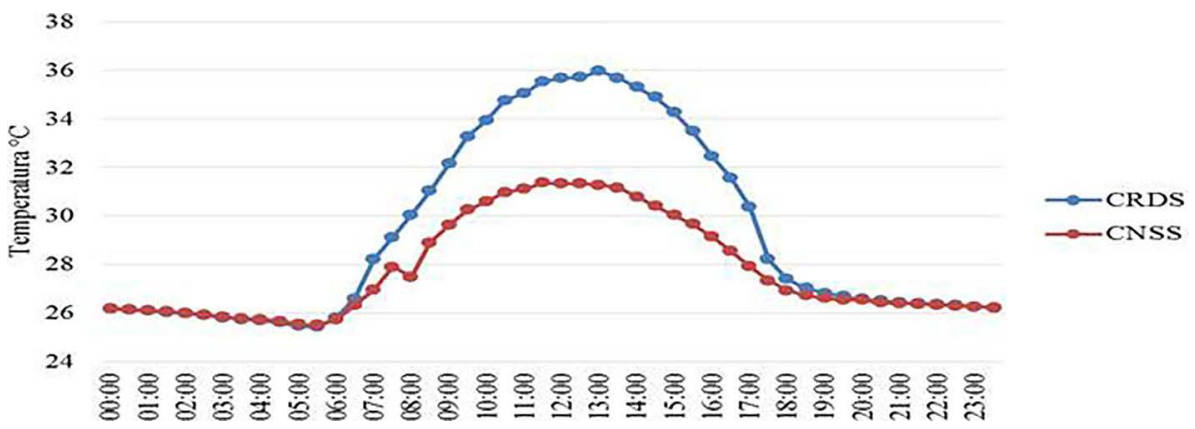

Figura 3 - Distribuição da média da temperatura externa (ambiente) por tratamento e hora do dia.

entre os tratamentos, onde o CRDS obteve a maior temperatura externa (ambiente) média $\left(33,26^{\circ} \mathrm{C}\right)$ enquanto o CNSS foi $29,85^{\circ} \mathrm{C}$, dentro do interstício de 7 às $17 \mathrm{~h}$.

\subsection{Temperaturas médias internas e externas versus comportamento forrageiro}

Na Fig. 4 foram relacionadas à média das temperaturas internas das colmeias com a média das temperaturas externas (ambiente), ambas do tratamento CRDS, somente nos dias em que houve avaliação do comportamento forrageiro de entrada das abelhas. O comportamento entre as temperaturas interna e externa é visto de forma similar quanto à curvatura das linhas, no entanto nota-se que entre as 10 e $17 \mathrm{~h}$ a temperatura externa do tratamento CRDS é menor que a temperatura interna do mesmo tratamento.

Apesar de não ser perceptível nenhum padrão em relação à temperatura interna, externa e comportamento forrageiro de entrada das abelhas, no tratamento CRDS é salutar observar que no horário compreendido entre $10 \mathrm{e}$ $12 \mathrm{~h}$ nota-se um aumento substancial no comportamento forrageiro das colônias do referido tratamento. Podemos apontar que esse aumento está ligado a termorregulação colonial, pois justamente nos momentos em que as temperaturas interna e externa (ambiente) são maiores, entram mais abelhas na colmeia. Possivelmente, a maior parte das abelhas poderia estar entrando com gotículas de água para refrigerar as colmeias. 


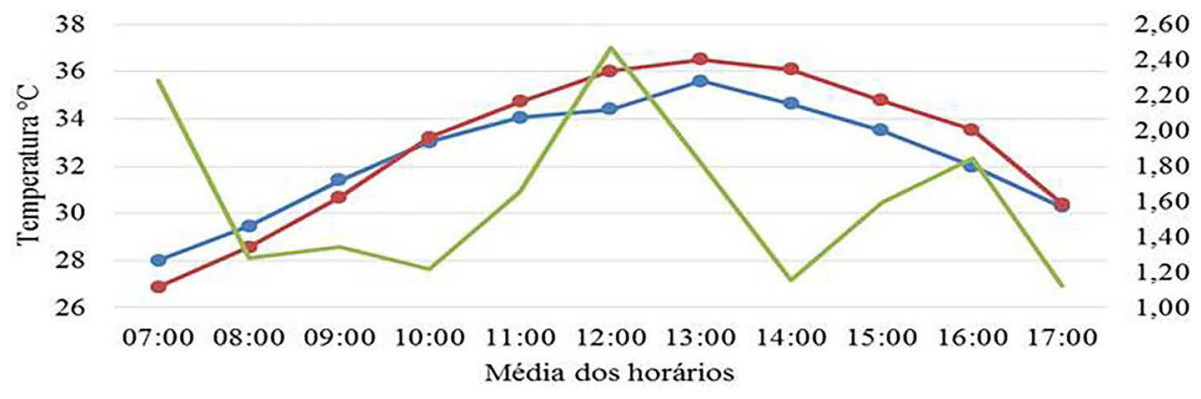

$\multimap$ Temperatura externa $\multimap$ Temperatura interna $\longrightarrow$ Entrada

Figura 4 - Distribuição das médias das temperaturas (interna e externa) do tratamento CRDS versus comportamento forrageiro (número médio de abelhas) e hora do dia.

Essa estratégia, conhecida como resfriamento evaporativo, consiste nas abelhas operárias coletarem água e distribuí-la por todo o ninho para que a temperatura interna seja reduzida pela evaporação da água. Segundo Domingos (2013), isso acontece porque para $1 \mathrm{~g}$ de água passar do seu estado liquido para o estado vapor são necessários aproximadamente $2.400 \mathrm{~kJ}$ de energia térmica.

Na Fig. 5 foram relacionadas à média das temperaturas internas das colmeias com a média das temperaturas externas (ambiente), ambas do tratamento CNSS, somente nos dias em que houve avaliação do comportamento forrageiro de entrada das abelhas. O comportamento entre as temperaturas interna e externa é visto também de forma similar quanto à curvatura da linha, no entanto, nota-se que entre 11 e $17 \mathrm{~h}$ a temperatura externa do tratamento CNSS é menor que a temperatura interna do mesmo tratamento. É possível notar também que quando a temperatura (tanto interna como externa) aumenta, a atividade de entrada das abelhas tende a diminuir, principalmente às 14 h, além da redução na quantidade de entrada das abelhas no final da tarde após as $16 \mathrm{~h}$. Ao contrário do que fora observado nas colônias do tratamento CRDS, as colônias do tratamento CNSS tiveram um comportamento forrageiro relativamente estável entre as 10 e $12 \mathrm{~h}$, evidenciando que as condições climáticas pareciam ser ideais para a continuidade das atividades das colmeias.
Portanto, ficou evidenciado que de fato há uma diferença significativa em relação ao comportamento forrageiro das abelhas para os dois tratamentos (CRDS e CNSS) em função das temperaturas (interna e externa), mostrando que elas tendem a se adaptar de acordo com as condições climáticas. Partindo dessa observação podemos apontar que a temperatura foi fator influenciador no comportamento forrageiro de entrada desses insetos.

A temperatura tem mostrado forte influência em diferentes outros aspectos do comportamento das abelhas. Apesar da insuficiência de estudos para abelhas jandaíra (sem ferrão) nesse contexto, para abelhas africanizadas com ferrão Queiroga et al. (2014) afirmaram que o comportamento agressivo dessas abelhas é diminuído quando das 7:00 às 10:00 da manhã, assim permitindo recomendar esse horário como o mais adequado para o manejo dessas abelhas. Também, outro exemplo, Malerbo-Souza e Silva (2011) que estudaram o comportamento forrageiro das abelhas africanizadas, verificaram diferenças significativas tanto para coleta de néctar quanto para de pólen em função da temperatura no decorrer do ano.

\subsection{Temperaturas médias internas versus temperaturas médias externas}

Ao comparar as temperaturas médias internas e externas do tratamento CNSS (Fig. 6), foi possível perceber

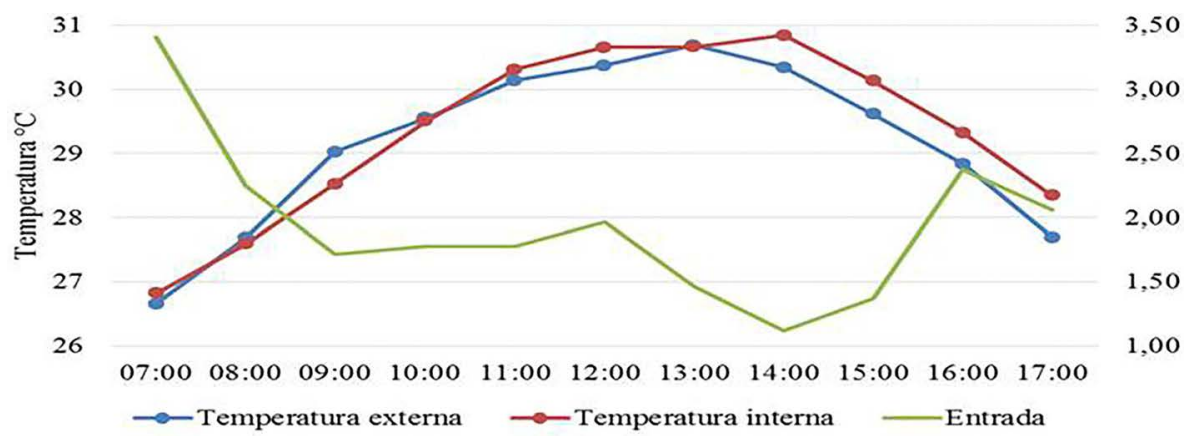

Figura 5 - Distribuição das médias das temperaturas (interna e externa) do tratamento CNSS versus comportamento forrageiro (número médio de abelhas) e hora do dia. 
que as abelhas em área sombreada tendem a termorregular as temperaturas internas das colmeias $\left(25,89\right.$ a $\left.31,85^{\circ} \mathrm{C}\right)$ de modo ligeiramente mais alto que a temperaturas externas $\left(25,4\right.$ a $\left.31,5^{\circ} \mathrm{C}\right)$. Ficou aparente que as essas abelhas se adequaram bem as condições climáticas do experimento, corroborando com as observações feitas de aumento no comportamento forrageiro e capacidade defensiva da colmeia.

Por sua vez, nas colônias do tratamento CRDS sem sombreamento (Fig. 7) foi possível notar que as temperaturas médias internas das colmeias $\left(24,89\right.$ a $\left.36,98{ }^{\circ} \mathrm{C}\right)$ foram maiores que as temperaturas externas $(25,4$ a $36,2^{\circ} \mathrm{C}$ ), apenas durante o dia, pois a noite ocorre o inverso. Esse fato pode apontar para uma possível dificuldade dessas abelhas em termorregular as temperaturas internas das colmeias durante o dia (especialmente entre as 10 e $16 \mathrm{~h}$ ) de modo a complicar sua adaptação à condição climática imposta, o que corrobora com as observações feitas de redução no comportamento forrageiro e na capacidade defensiva. Ademais, o comportamento forrageiro das abelhas desse tratamento (CRDS) foi maior, justamente, nos horários de picos da temperatura externa, fortalecendo a hipótese de que naquele momento esses insetos estivessem trazendo gotículas d'água para dentro da colmeia a fim de refrigerá-la.

\subsection{Temperaturas médias interna e externa CRDS versus CNSS}

Ao comparar o comportamento das temperaturas médias interna e externa dos tratamentos CRDS e CNSS (Fig. 8), verificou-se que entre os tipos de temperatura (interna e externa) de um mesmo tratamento os valores são bastante próximos em ambos os tratamentos separadamente. Porém, quando comparamos temperaturas internas de tratamentos diferentes (CRDS e CNSS) é visível a diferença entre elas. $\mathrm{O}$ mesmo ocorre quando comparamos temperaturas externas de tratamentos diferentes (CRDS e CNSS).

Estabelecendo o nível de significância de 0,05 , concluiu-se que há diferença significativa $(\mathrm{p}=0,02)$ entre os tratamentos CRDS e CNSS quando comparamos as temperaturas médias internas ou quando comparamos as temperaturas médias externas. No entanto não houve diferença significativa quando comparamos temperatura interna e externa de um mesmo tratamento. Essas informações foram avaliadas com base na média dos horários durante $24 \mathrm{~h}$ avaliadas a cada $30 \mathrm{~min}$. Porém, a mesma análise também mostrou que há diferença significativa quando essa comparação é entre curva de temperatura média interna de um tratamento com outro, assim como também há diferença significativa quando essa comparação é entre curva de temperatura média externa de um tratamento com outro. Isso força-nos a dizer que as condições térmicas dos tratamentos são diferentes significativamente.

Esse fato mostra que apesar das abelhas de ambos os tratamentos terem se adequado a condição climática imposta, as abelhas do tratamento CRDS sofreram mais nesse processo adaptativo com mudanças negativas no comportamento forrageiro e na capacidade defensiva. Considerando o processo acelerado de degradação do bioma Caatinga, incluindo-se aí o desmatamento da vegetação nativa, o processo de desertificação acelerado, redução nos índices pluviométricos e, principalmente, o aumento da temperatura média, fica uma acentuada e impetuosa dúvida sobre a capacidade de resiliência da espécie de abelhas jandaíras dentro desse cenário.

\section{Conclusões}

Neste trabalho foram apresentados resultados referentes à variação de temperatura ambiente e seus impactos em colônias de abelhas jandaíras (Melipona subnitida Ducke), uma espécie endêmica do Nordeste do Brasil com alto potencial para produção de mel e um dos principais polinizadores do bioma Caatinga.

Os resultados mostraram que a temperatura interna das colméias de abelhas jandaíras dos tratamentos CRDS e CNSS sofreu influência direta da temperatura externa (ambiente) e que a exposição de colônias diretamente ao

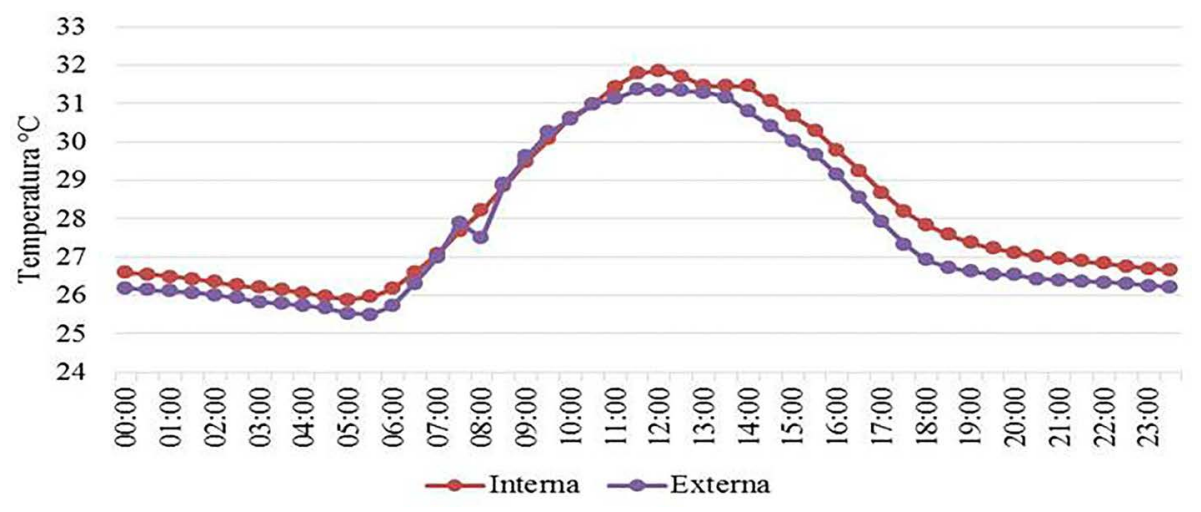

Figura 6 - Distribuição da média da temperatura interna e da média da temperatura externa, do tratamento CNSS, durante o experimento. 


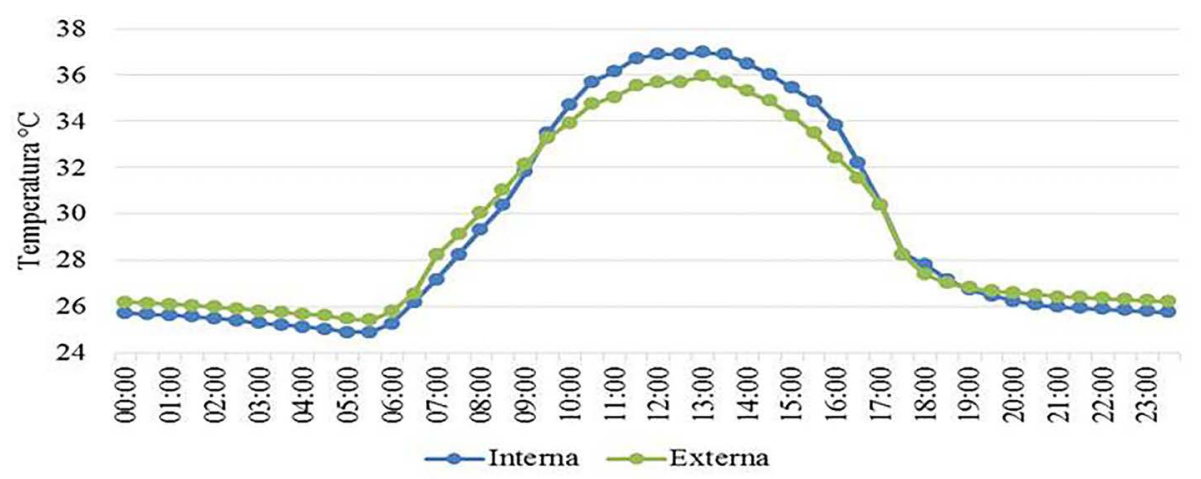

Figura 7 - Distribuição da média da temperatura interna e da média da temperatura externa, do tratamento CRDS, durante o experimento.

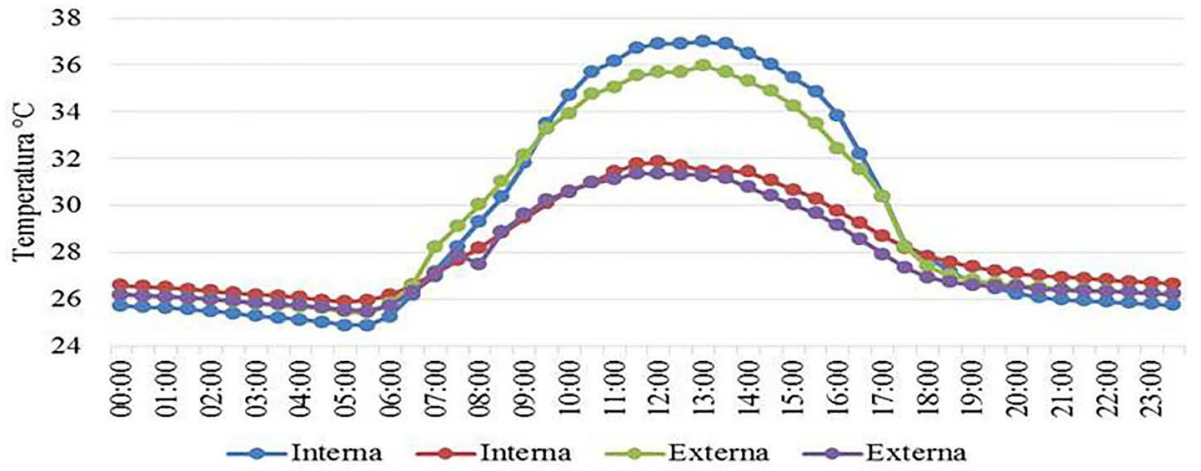

Figura 8 - Distribuição da média da temperatura (interna e externa) em relação aos horários avaliado nos tratamentos CRDS e CNSS, durante o experimento.

sol (CRDS), promoveu redução no comportamento forrageiro de entrada e redução considerável na capacidade defensiva da colmeia. As colônias de abelhas jandaíras expostas diretamente ao sol, aparentaram mais dificuldade para termorregular as colmeias e adaptar-se a essa condição, do que as colônias que estavam em área totalmente sombreada (CNSS), evidenciando uma possível "fadiga" das tais colônias por conta da temperatura. Portanto, parece razoável sugerir que locar as colmeias em áreas de sombreamento natural perene, possa ser uma medida de ajuste preventivo ao aumento da temperatura ambiente previsto para os anos vindouros.

Fazendo uma reflexão da relação entre o possível aumento da temperatura do ar, conforme previsto no último relatório do IPCC (AR5), e nossos achados para as colônias de abelhas jandaíras, bem como estendendo para outras espécies de abelhas nativas do bioma Caatinga, podemos pensar que existe uma perspectiva de dificuldade para as espécies de abelha frente às condições climáticas projetadas para o futuro médio (2046-2065) e de longo prazo (2080-2099). Embora as alterações nas temperaturas médias globais sejam um fenômeno em nível global, suas consequências são enfrentadas em nível local.

Nesse sentido, a implantação de ações voltadas à adaptação das atividades econômicas ao fenômeno, à conscientização da população quanto ao uso sustentável dos recursos naturais e à formação educacional para adaptação às condições climáticas regionais vindouras, podem ajudar a mitigar efeitos negativos decorrentes das mudanças climáticas sobre o bioma Caatinga.

\section{Referências}

BELLARD, C.; BERTELSMEIER, C.; LEADLEY, P.; THUILLER, W.; COURCHAMP, F. Impacts of climate change on the future of biodiversity. Ecology Letters, v. 15, n. 4, p. 365-377, 2012.

BONATTI, V.; SIMÕES, Z.L.P.; FRANCO, F.F.; FRANCOY, T. M. Evidence of at least two evolutionary lineages in Melipona subnitida (Apidae, Meliponini) suggested by mtDNA variability and geometric morphometrics of forewings. Naturwissenschaften, v. 101, n. 1, p. 17-24, 2014.

BRASIL. Ministério do Meio Ambiente. Plano Nacional de Adaptação à Mudança do Clima: Estratégias Setoriais e Temáticas. Brasília: MMA, 2016a. 295p.

BRASIL. Ministério do Meio Ambiente. Brasil: $5^{\circ}$ Relatório Nacional para a Convenção Sobre Diversidade Biológica. Brasília: MMA, 2016b. 240p.

CARADONNA, P.J.; CUNNINGHAM, J.L.; ILER, AM. Experimental warming in the field delays phenology and reduces body mass, fat content and survival: Implications for the 
persistence of a pollinator under climate change. Funct Ecol. v. 32, n. 10, p. 2345-2356, 2018.

CBD - Convention on Biological Diversity. Biodiversity and Climate Change: Making Use of the Findings of the IPCC's Fifth Assessment Report. Montreal: UNEP, 2016. $10 \mathrm{p}$.

DOMINGOS, H.G.T.; MAIA, A.S.C.; SOUZA JR, J.B.F.; SILVA, R.B.; VIEIRA, F.M.C.; SILVA, R.G. Effect of shade and water sprinklin $g$ on physiological responses and milk yields of Holstein cows in a semi- arid region. Livestock Science, v. 154, n. 1, p. 169-174, 2013.

ICMBIO - Instituto Chico Mendes de Conservação da Biodiversidade. Livro Vermelho da Fauna Brasileira Ameaçada de Extinção: Volume VII - Invertebrados. Brasília, DF, ICMBio/MMA, 2018. 727p.

IPCC - Intergovernmental Panel on Climate Change. Climate Change 2014: Synthesis Report. Contribution of Working Groups I, II and III to the Fifth Assessment Report of the Intergovernmental Panel on Climate Change. Core Writing Team, R.K. Pachauri and L.A. Meyer (eds.). IPCC, Geneva, 2014. 151p.

LACERDA, F.F.; NOBRE, P.; SOBRAL, M.C.M.; LOPES, G. M.B.; ASSAD, E.D.; Tendência do clima do semiárido frente as perspectivas das mudanças climáticas globais; o caso de Araripina, Pernambuco. Revista do Departamento de Geografia da USP, v. 31, p. 132-141, 2016.

LIMA, M. V. Respostas de Apis mellifera L. A Diferentes Condições Térmicas. 2016. 52 f. Dissertação (Mestrado em Zootecnia) - Centro de Ciências Agrárias, Universidade Federal da Paraíba, Areia, 2016.

MALERBO-SOUZA, D.T.; SILVA, F.A.S. Comportamento forrageiro da abelha africanizada Apis mellifera L. no decorrer do ano. Acta Scientiarum. Animal Sciences, v. 33, n. 2, p. 183-190, 2011.
MARENGO, J.A. Vulnerabilidade, impactos e adaptação à mudança do clima no semi-árido do Brasil. Parcerias Estratégicas, v. 13, n. 27, p. 149-175, 2008.

MARENGO, J.A. O futuro clima do Brasil. Revista USP, n. 103, p. 25-32, 2014.

MARENGO, J.A.; TORRES, R.R.; ALVES, L.M. Drought in Northeast Brazil - past, present, and future. Theoretical and Applied Climatology, v. 129, n. 3, p. 1189-1200, 2017.

PECL, G.T.; ARAUJO, M.B.; BELL, J.; BLANCHARD, J.; BONEBRAKE, T.C. et al. Biodiversity redistribution under climate change: Impacts on ecosystems and human well-being. Science, v. 355, n. 6332, p. 1-9, 2017.

QUEIROGA, V.P.P.; SILVEIRA, D.C.; LEITE, D.T.; SAMPAIO, R.B.; LUCAS, C.I.S. et al. Influência da temperatura e da alimentação na defensividade de abelhas africanizadas nas condições do semiárido paraibano. Revista ACSA, v. 10, n. 1, p. 102-110, 2014.

SEDDON, A.W.R.; MACIAS-FAURIA, M.; LONG, P.R.; BENZ, D.; WILLIS, K.J. Sensitivity of global terrestrial ecosystems to climate variability. Nature, v. 531, p. 229232, 2016.

SHACKLETON, K.; AL TOUFAILIA, H.; BALFOUR, N.J.; ALVES, D.A.; RATNIEKS, F.L.W. Appetite for self-destruction: suicidal biting as a nest defense strategy in Trigona stingless bees. Behavioral Ecology and Sociobiology, v. 69, n. 2, p. 273-281, 2015.

VON FRISCH K. Bees: Their Vision, Chemical Senses and Language. London: Cornell University Press, 1976. 154 p.

License information: This is an open-access article distributed under the terms of the Creative Commons Attribution License (type CC-BY), which permits unrestricted use, distribution and reproduction in any medium, provided the original article is properly cited. 